\title{
NLS-RAR $\alpha$ is a novel transcriptional factor
}

\author{
KAI-LING JIANG ${ }^{1,3}$, LIANG ZHONG ${ }^{1}$, XIAO-QUN YANG ${ }^{2}$, \\ PENG-PENG MA ${ }^{2}$, HUI WANG ${ }^{2}$, XIN-YU ZHU ${ }^{2}$ and BEI-ZHONG LIU ${ }^{1,2}$
}

\begin{abstract}
${ }^{1}$ Central Laboratory of Yongchuan Hospital, Chongqing Medical University, Chongqing 402160; ${ }^{2}$ Key Laboratory of Laboratory Medical Diagnostics, Ministry of Education, Department of Laboratory Medicine, Chongqing Medical University, Chongqing 400016; ${ }^{3}$ Clinical Laboratory of Liangping District People's Hospital, Chongqing 405200, P.R. China
\end{abstract}

Received April 6, 2016; Accepted June 9, 2017

DOI: $10.3892 / \mathrm{ol} .2017 .7132$

\begin{abstract}
Acutepromyelocytic leukemia(APL) ischaracterized by the presence of the promyelocytic leukemia (PML)-retinoic acid receptor- $\alpha$ (RAR- $\alpha$ ) fusion protein. PML-RAR $\alpha$ can be cleaved by neutrophil elastase (NE) in several positions in cells in the promyelocytic stage, nuclear location signal (NLS)-negative PML and NLS-RAR $\alpha$ may be the products of PML-RAR $\alpha$ by NE. The function of NLS-RAR $\alpha$ may be affected by the addition of NLS, which would alter its localization in cells, as the role of NLS is to identify proteins for transport to the nucleus. Preliminary experiments demonstrated that the overexpression of NLS-RAR $\alpha$ in HL-60 cells could promote cellular proliferation and inhibit cellular differentiation. Following treatment with all-trans retinoic acid (ATRA), the degree of cellular differentiation was enhanced. In the present study, the localization of NLS-RAR $\alpha$ was identified and its activity as a novel transcriptional factor was assessed, which may be critical in the development of APL. The location of NLS-RAR $\alpha$ was detected in the nucleus and cytoplasm by indirect immunofluorescence and western blot analysis, with expression in the nucleus revealed to be increased compared with that in the cytoplasm. Next, native-PAGE was performed and NLS-RAR $\alpha$ and RXR $\alpha$ were revealed to form heterodimers in the nucleus. In addition, co-immunoprecipitation revealed an interaction between NLS-RAR $\alpha$ and retinoid $X$ receptor- $\alpha(R X R \alpha)$. An electrophoresis mobility shift assay (EMSA) indicated that NLS-RAR $\alpha$ could bind retinoic acid response elements (RAREs) in the presence of ATRA. Indeed, NLS-RAR $\alpha$ could bind RAREs just as WTRAR $\alpha$ could, including the RAREs direct repeat-2 (DR-2) and DR-5. In addition, results from a luciferase reporter gene assay demonstrated that NLS-RAR $\alpha$ could mediate the activity of RAREs that it bound. Together, these results indicated that NLS-RAR $\alpha$
\end{abstract}

Correspondence to: Professor Bei-Zhong Liu, Central Laboratory of Yongchuan Hospital, Chongqing Medical University, 439 Xuan Hua Road, Chongqing 402160, P.R. China

E-mail: liubeizhong@cqmu.edu.cn

Key words: acute promyelocytic leukemia, retinoic acid receptor- $\alpha$, retinoic acid receptor- $\alpha$ nuclear location signal, retinoic acid response elements may be a novel transcription factor that contributes to leukemogenesis by competitively binding RAREs as heterodimers with RXR $\alpha$, just as PML-RAR $\alpha$ does, thus repressing the gene transcription essential for myeloid differentiation. These findings indicate the potential role of NLS-RAR $\alpha$ targeted therapy in APL.

\section{Introduction}

Acute promyelocytic leukemia (APL) is a clonal disease characterized by the dysregulated proliferation of abnormal promyelocytes. A non-random chromosomal translocation breakpoint,t(15;17)(q22;q21), occurs in almost every APL patient, which produces the promyelocytic leukemia (PML)-retinoic acid receptor- $\alpha$ (RAR- $\alpha$ ) fusion gene, resulting in the expression of the PML-RAR $\alpha$ fusion protein (1). Other fusion genes that cause APL also exist, including promyelocytic leukemia zinc finger protein-RAR $\alpha$ and nucleophosmin-RAR $\alpha$ (2). The $\mathrm{RAR} \alpha$ gene is a target of chromosomal rearrangements in all cases of acute promyelocytic leukemia (APL), with each fusion protein containing the same portion of the RAR $\alpha$ polypeptide (which includes the DNA-binding and ligand-binding domains (3), a fact that highlights the key roles served by RAR $\alpha$ in the development of APL $(4,5)$.

RAR $\alpha$ belongs to the nuclear receptor family and has a proven role in the differentiation of myeloid cell lines; it is also a transcriptional regulator that binds to specific retinoic acid response elements (RAREs) present in the promoters of RAR $\alpha$-target genes as a heterodimer with nuclear receptor retinoid X receptor- $\alpha(\operatorname{RXR} \alpha)$ (6). Numerous observations indicate that PML-RAR $\alpha$ is a potent repressor of promelocyte differentiation $(7,8)$. PML-RAR $\alpha$ contributes to leukemogenesis by competitive binding of RAREs, either as a homodimer or as a heterodimer with wild-type (WT) RAR $\alpha(9,10)$, thereby repressing gene transcription essential for myeloid differentiation. In the past few years, the development of curative approaches for APL has been the paradigm (11), but the specific mechanistic network of APL is still not fully understood (12-14). It is therefore urgent to understand more about the molecular mechanism of APL in order to develop improved, targeted drugs for the treatment of APL.

Nuclear location signal (NLS)-RAR $\alpha$ is a cleavage variant of PML-RAR $\alpha$, formed on cleavage by neutrophilelastase (NE), an early-myeloid-specific serine protease, whose production 
is maximal in promyelocytes. NE-deficient animals were reported to be protected from development of APL $(15,16)$. The NLS is a short sequence of amino acids that mediates the transport of nuclear proteins into the nucleus. Typically, deletion of the NLS disrupts nuclear import (17); however, the addition of NLS to RAR $\alpha$ alters the localization of this fusion protein. Several reports indicated that protein localization alters protein functions (18-20). We hypothesized that the genes transcribed by RAR $\alpha$ and NLS-RAR $\alpha$ were similar and perhaps that NLS-RAR $\alpha$ had a gain of function compared to WTRAR $\alpha$. NLS-RAR $\alpha$, following cleavage by NE, may have increased function compared with RAR $\alpha$, possibly dependent on protein localization and RARE-binding activity; similarities exist between NLS-RAR $\alpha$ and the PML-RAR $\alpha$ fusion protein. The aim of the present study was to examine the localization of NLS-RAR $\alpha$ and the functional changes that the addition of this signal mediated. These findings may provide important information on the occurrence and development of APL.

\section{Materials and methods}

Cell culture and plasmid construction. The NB4, K562 and HEK293 cell lines were purchased from the Shanghai Institutes for Biological Sciences (Shanghai, China). The NB4 and K562 cell lines were cultured in RMPI-1640 medium (Gibco; Thermo Fisher Scientific, Inc., Waltham, MA, USA) supplemented with $10 \%$ fetal bovine serum (Gibco; Thermo Fisher Scientific, Inc.); the HEK 293 cell line was cultured in Dulbecco's modified Eagle's medium (DMEM; Gibco; Thermo Fisher Scientific, Inc.) containing 10\% fetal bovine serum (Gibco; Thermo Fisher Scientific, Inc.). All cells were cultured in an environment with $5 \% \mathrm{CO}_{2}$ at $37^{\circ} \mathrm{C}$, and the culture liquid was changed every day. The culture liquid was changed every day. The RAR $\alpha$ and $\mathrm{RXR} \alpha$ expression constructs used for in vitro translation were generated by polymerase chain reaction (PCR) amplification of the corresponding regions of complementary DNA (cDNA) in NB4 cells and cloned into the expression vectors PCMV-HA and PCMV-mycvectors, respectively (BioVector NTCC, Inc., Beijing, China). The thermocycling conditions of RAR $\alpha$ were: $95^{\circ} \mathrm{C}$ for $5 \mathrm{~min}, 98^{\circ} \mathrm{C}$ for $10 \mathrm{sec}, 62^{\circ} \mathrm{C}$ for $35 \mathrm{sec}, 72^{\circ} \mathrm{C}$ for $90 \mathrm{sec}$ and $72^{\circ} \mathrm{C}$ for $5 \mathrm{~min}$. The thermocycling conditions of RXR $\alpha$ were: $95^{\circ} \mathrm{C}$ for $5 \mathrm{~min}$, $98^{\circ} \mathrm{C}$ for $10 \mathrm{sec}, 59.5^{\circ} \mathrm{C}$ for $35 \mathrm{sec}, 72^{\circ} \mathrm{C}$ for $90 \mathrm{sec}$ and $72^{\circ} \mathrm{C}$ for $5 \mathrm{~min}$. The DNA polymerase was purchased from Takara Biotechnology Co., Ltd., Dalian, China. The primers of RAR $\alpha$ and RXR $\alpha$ were: RAR $\alpha$ forward, 5'-CCGGTCGACAGATGT ACGAGAGTGTAGAAG-3' (EcoRV sequence underlined) and reverse, 5'-CCGGATATCGTCACATGGTCGGTAG-3 (SalI sequence underlined); and RXR $\alpha$ forward, 5'-CCTGAA TTCATGGACACCAAACATTTCCTGC-3' (EcoRI sequence underlined) and reverse, 5'-CCTGCGGCCGCCTAAGTC ATTTGGTGCGGC-3' (NotI sequence underlined). All primers were synthesized by Takara Biotechnology Co., Ltd. NLS-RAR $\alpha$ was amplified using pcDNA3.1-PML-RAR $\alpha$ as a template, and then subcloned into PCMV-HA vectors.

RNA extraction and plasmid construction. Total RNA from NB4 cells was extracted using TRIzol reagent (Invitrogen; Thermo Fisher Scientific Inc.) and reverse transcribed using a PrimeScript RT reagent kit (Takara Biotechnology Co.,
Ltd.). The PCR reaction mixture contained $2 \mu \mathrm{l}$ cDNA, $1 \mu \mathrm{l}(20 \mu \mathrm{M})$ of each primer and $25 \mu 1$ PremixTaq enzyme (Takara Biotechnology Co., Ltd.), with sterile water added up to a final volume of $50 \mu \mathrm{l}$. The reaction conditions were: Pre-denaturation at $95^{\circ} \mathrm{C}$ for $5 \mathrm{~min}$, and then 35 cycles of denaturation at $98^{\circ} \mathrm{C}$ for $10 \mathrm{sec}$, annealing at $62^{\circ} \mathrm{C}$ (for $\operatorname{RAR} \alpha$ ) $/ 59.5^{\circ} \mathrm{C}$ (for $\mathrm{RXR} \alpha$ ) for $90 \mathrm{sec}$, extension at $72^{\circ} \mathrm{C}$ for $30 \mathrm{sec}$. The PCR products were separated on $1.5 \%$ agarose gels and stained with ethidium bromide. The fragments were then recycled from the gel and for RAR $\alpha$, the fragment and a PCMV-HA empty vector was digested with EcoRV and SalI (Takara Biotechnology Co., Ltd.); for RXR $\alpha$, the fragment and PCMV-myc empty vector was digested with EcoRI and NotI (Takara Biotechnology Co., Ltd.), and the digested fragments and vector were ligated with T4 ligase for $6 \mathrm{~h}$. The ligation product was then transformed into competent Escherichia coli. The transformation process was as follows: The ligation product was added to competent $E$. coli $\mathrm{DH} 5 \alpha$, which were placed in an ice bath for $30 \mathrm{~min}$, heat shocked immediately for $90 \mathrm{sec}$ at $42^{\circ} \mathrm{C}$, placed into an ice bath for $2 \mathrm{~min}$, and then the present study added $800 \mu \mathrm{l}$ antibiotic-free lysogeny broth. After this step, the broth underwent shaking for 30-60 min at $37^{\circ} \mathrm{C}$ and $220 \mathrm{rpm}$; centrifugation for $5 \mathrm{~min}$ at $1,0006.2 \mathrm{x} \mathrm{g}$ produced $\sim 100 \mu \mathrm{l}$ supernatant. Following the resuspension of the precipitate with the supernatant, and the coating of the LB plates with $50 \mu \mathrm{g} / \mathrm{mlkanamycin}$, the plates were placed in a culture incubator at $37^{\circ} \mathrm{C}$. Transformed colonies were selected using the kanamycin and, $12 \mathrm{~h}$ later, were shaken in $5 \mathrm{ml}$ lysogenybroth at $37^{\circ} \mathrm{C}$. After $12 \mathrm{~h}$, the plasmids were extracted using a PureYield ${ }^{\mathrm{TM}}$ Plasmid Maxiprep System kit purchased from Promega Corporation (Madison, WI, USA) and sent to Takara Biotechnology Co., Ltd. for sequencing.

Transfection and preparation of the cell extracts. A total of $1 \times 10^{7}$ HEK293 cells were seeded into10-cm dishes. Prior to transfection, the cells were cultured with DMEM for $1 \mathrm{~h}$ then transiently transfected with PCMV-HA-NLS-RAR $\alpha$ $(8 \mu \mathrm{g})$ and PCMV-myc-RXR $\alpha(8 \mu \mathrm{g})$ with Lipofectamine ${ }^{\circledR}$ 2000 (30 $\mu$ l; Invitrogen; Thermo Fisher Scientific, Inc.) when cell confluence reached over $80 \%$. At $6 \mathrm{~h}$ after transfection, DMEM was replaced with DMEM supplemented with $10 \%$ fetal bovine serum. After 2 days, the cells were collected into Eppendorf tubes and centrifuged at $96.8 \mathrm{x} \mathrm{g}$ for $5 \mathrm{~min}$ at $4^{\circ} \mathrm{C}$, washed three times with cold PBS and suspended in radioimmunoprecipitation assay buffer and phenylmethylsulfonyl fluoride (at a ratio of 100:1) on ice. This lysis buffer contained cell extraction reagents $\mathrm{A}$ and $\mathrm{B}$ that used low osmotic pressure conditions to lyse cell membranes, releasing cytoplasmic protein. The extraction of cell proteins was achieved using a Protein Extraction kit purchased from the Beyotime Institute of Biotechnology (Haimen, China) and was performed according to the manufacturer's protocol. Nuclear proteins were obtained using a nuclear protein extraction reagent kit (P0027) purchased from the Beyotime Institute of Biotechnology in accordance with the manufacturer's protocol. The cells were then centrifuged at 15,000 x $\mathrm{g}$ for $15 \mathrm{~min}$ at $37^{\circ} \mathrm{C}$, the supernatant was collected and the protein concentration was measured using a BCA assay kit (P0009) purchased from the Beyotime Institute of Biotechnology in accordance with the manufacturer's protocol. 
A

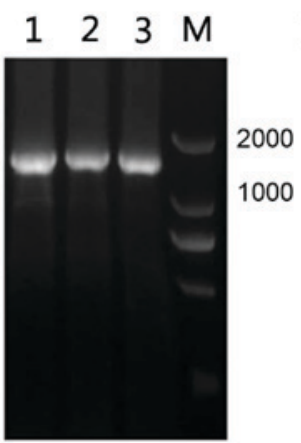

D

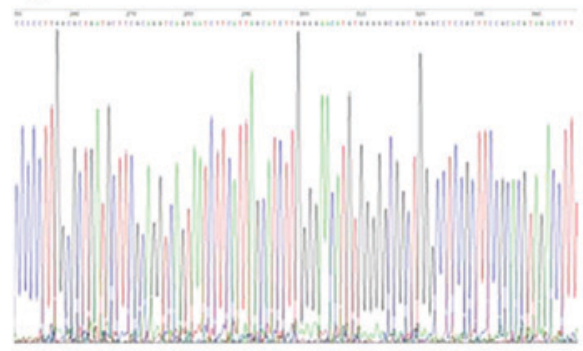

B $\quad \begin{array}{llll}1 & 2 & 3 & M\end{array}$

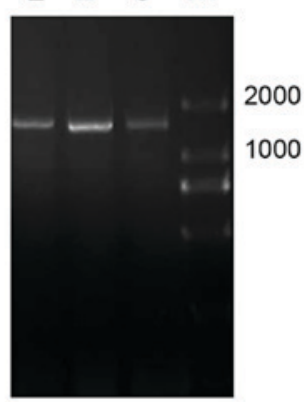

2000

1000

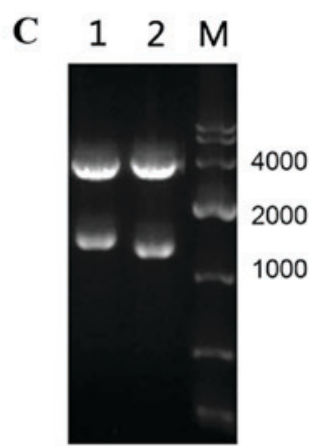

E

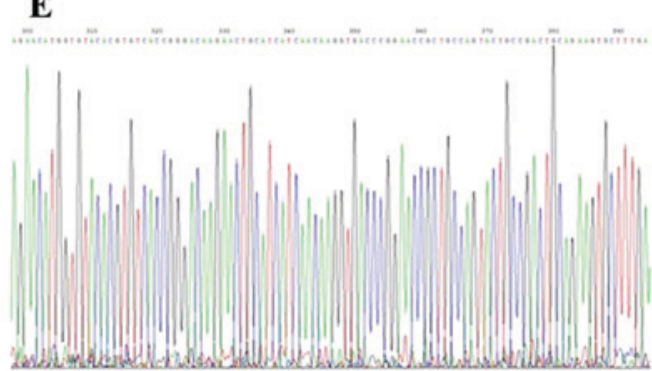

Figure 1. Construction of expression plasmids. (A) PCR result of RXR $\alpha$. (B) PCR result of RAR $\alpha$. (C) Verification of plasmid expression (1, pCMV-HA-RAR $\alpha$; 2, pCMV-myc-RXR $\alpha$ ). (D) Partial sequencing of the pCMV-HA-RAR $\alpha$ plasmid. (E) Partial sequencing of the pCMV-myc-RXR $\alpha$ plasmid. PCR, polymerase chain reaction; $\mathrm{RXR} \alpha$, retinoid $\mathrm{X}$ receptor- $\alpha$; $\mathrm{RAR} \alpha$, retinoic acid receptor- $\alpha$.

Co-immunoprecipitation (Co-IP) and western blot analysis. A total of $1 \times 10^{7}$ cells were seeded in $10-\mathrm{cm}$ dishes and $48 \mathrm{~h}$ after transfection, cells were lysed using IP lysis buffer from an NP-40 kit (P0013F) purchased from the Beyotime Institute of Biotechnology. The cell extracts were then incubated with the appropriate antibodies, if adding anti-RAR $\alpha$ antibody at a given step, the present study would use anti-RXR $\alpha$ antibody in the following step and vice versa, or non-specific controls. Immunocomplexes were recovered by protein $\mathrm{A} / \mathrm{G}$ agarose beads and resolved by electrophoresis. Cell protein $(40 \mu \mathrm{g})$ from each group was separated by $10 \%$ SDS-PAGE and then transferred onto a polyvinylidene difluoride (PVDF) membrane. These membranes were incubated for $3 \mathrm{~h}$ at room temperature in 5\% skimmed milk [diluted with Tris-buffered-saline with Tween-20 (TBST)] for membrane blocking. The primary antibodies used were anti-RAR $\alpha$ rabbit polyclonal antibody (cat. no. sc-551); anti-RXR $\alpha$ (cat. no. sc-46659) mouse monoclonal antibody (both diluted 1:1,000; Santa Cruz Biotechnology, Inc., Dallas, TX, USA). Membranes were incubated with primary antibodies overnight at $4{ }^{\circ} \mathrm{C}$ and then incubated with secondary antibody (goat anti-rabbit antibody; 1:2,000; cat. no. 127760; Beijing Zhongshan Golden Bridge Biotechnology Co., Ltd., Beijing, China) forl $\mathrm{h}$ at room temperature. After washing three times with TBST, immunoreactive complexes were visualized using ECL Chemiluminescence system (Bio-Rad Laboratories, Inc., Hercules, CA, USA). $\beta$-actin served as an internal positive control.

Immunofluorescence (IF) microscopy. Transfected HEK293 cells were cytospun onto slides, fixed in $4 \%$ formaldehyde for $20 \mathrm{~min}$, washed with PBS containing $0.1 \%$ Tween-20, permeabilized with $0.1 \%$ Triton X-100 solution for $10 \mathrm{~min}$ and washed three times with PBS. Cells were then blocked with $10 \%$ goat serum for $30 \mathrm{~min}$ at room temperature. After blocking, cells were immunolabelled with anti-RAR $\alpha$ 1:200 diluted rabbit polyclonal antibodies (cat. no. sc-551) and anti-RXR $\alpha$ 1:200 diluted mouse monoclonal antibodies (cat. no. sc-46659) raised in the lab at $4^{\circ} \mathrm{C}$ overnight, washed three times in PBS and then relabelled with fluorescein isothiocyanate (FITC)-coupled goat anti-rabbit (cat. no. ZF-0314; 1:200; Zhongshan Golden bridge Biotechnology Co., Ltd.) and tetramethylrhodamine (TRITC)-coupled goat anti-mouse antibodies (cat. no. ZF-0313; 1:200; Zhongshan Golden bridge Biotechnology Co., Ltd.) at room temperature for $1 \mathrm{~h}$. For nucleus staining, immunolabeled cells were incubated with DAPI or propidium iodide. A laser scanning confocal microscope was used to observe the cells.

Electrophoretic mobility shift assay (EMSA) and reporter gene assays. For the EMSA, the nuclear extract was obtained from HEK293 cells transiently transfected with PCMV-HA and PCMV-myc expression vector(s) containing NLS-RAR $\alpha$ and RXR $\alpha$ by washing cells in each group with ice-cold phosphate-buffered saline and lysing them in RIPA-1640 solution (Beyotime Institute of Biotechnology) containing a protease inhibitor cocktail for $20 \mathrm{~min}$ at $4^{\circ} \mathrm{C}$. After $24 \mathrm{~h}, 10^{-6} \mathrm{M}$ all-trans retinoic acid (ATRA) was added to the dishes. RAR $\alpha$ and RXR $\alpha$ genes were presented to the variety of the consensus binding sequences. Biotin-labeled DNA probes were synthesized by Takara Biotechnology Co., Ltd. and mixed with nuclear extract in the binding buffer as aforementioned, with $0.02 \mu \mathrm{g} / \mu \mathrm{l}$ poly (deoxyinosinic-deoxycytidylic) acid at room temperature. DNA-protein complexes and free DNA were separated on a $3.75 \%$ polyacrylamide gel. HEK293 cells were transiently transfected with luciferase reporter plasmids [RARE-2-Tk-Luc and DR5-(or 8)-Tk-Luc] and pCMV-HA-NLS-RAR $\alpha$, pCMV-HA-RAR $\alpha$ 
A

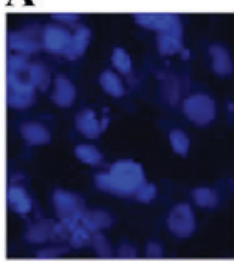

C

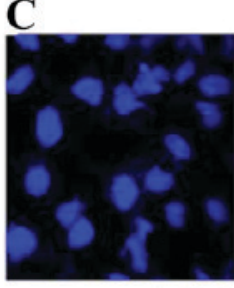

A:NLS-RAR $\alpha$

$\mathbf{E}$

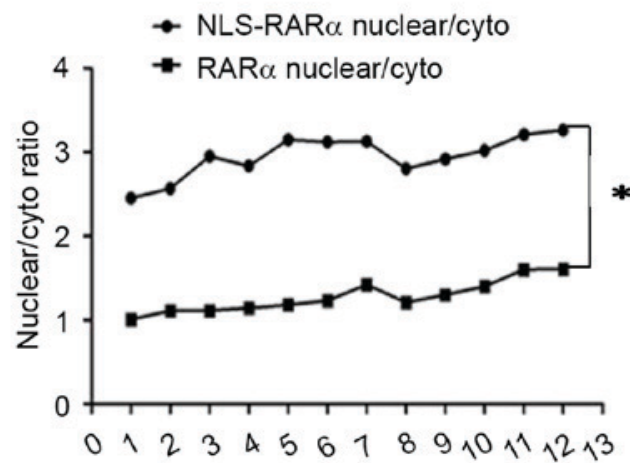

B

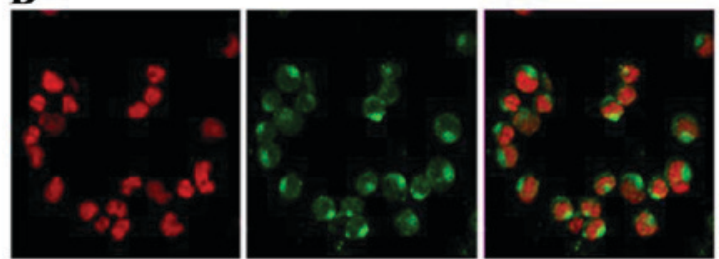

D
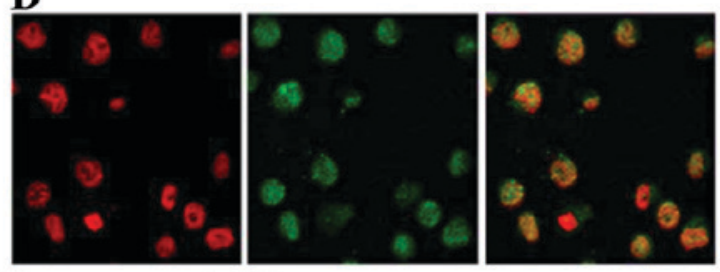

$\mathrm{C}: \mathrm{K} 562$

D:NB4

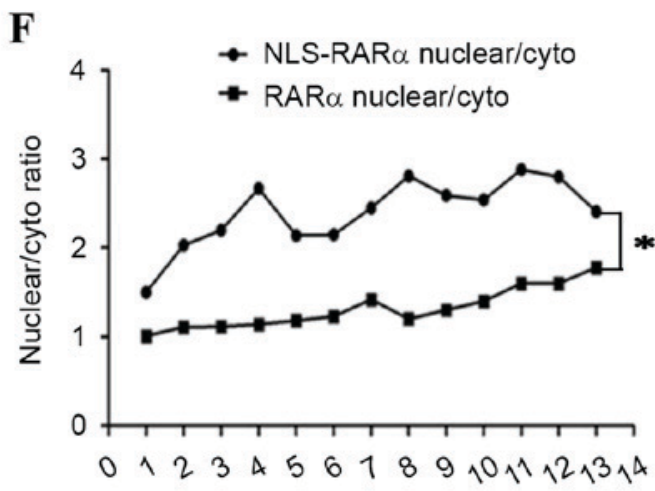

Figure 2. Distribution of RAR $\alpha$ and NLS-RAR $\alpha$ in different cell lines. (A and B) IF assay, the localization of RAR $\alpha$ and NLS-RAR $\alpha$ in HEK293 cells. (C) IF assay revealing the localization of RAR $\alpha$ in K562 cells. (D) IF assay, the localization of NLS-RAR $\alpha$ in NB4 cells. (E and F) Nuclear/plasma fluorescence ratio of RAR $\alpha$ and NLS-RAR $\alpha$ in (E) HEK293 and (F) NB4 cells. Data are expressed as the mean \pm SD. "P<0.05. IF, immunofluorescence; RAR $\alpha$, retinoic acid receptor- $\alpha$.

using Lipofectamine 2000 (Invitrogen; Thermo Fisher Scientific, Inc.). The luciferase reporter plasmids were donated by Professor Huguesde The (Institut Universitaire d'Hématologie, Université Paris-Diderot, Paris, France). After 48 h, cells were lysed and normalized luciferase activities were determined.

Statistical analysis. Independent sample t-test was used to compare the means between two groups. All statistical analyses were performed using the SPSS 18.0 software package (SPSS, Inc., Chicago, IL, USA). All data and results presented are representative of, or calculated from, at least three independentexperiments. $\mathrm{P}<0.05$ was considered to indicate a statistically significant difference.

\section{Results}

Plasmid construction. Firstly, RNA was extracted from APL cell line NB4, which was reverse transcribed into cDNA and then amplified by PCR (Fig. 1A and B). The lengths of RAR $\alpha, \operatorname{RXR} \alpha$ were 1,449 and 1,389 bp respectively. Next, the fragments were digested with the appropriate restriction endonucleases. Sequencing results verified that RAR $\alpha$ and $R X R \alpha$ expression plasmids had been constructed (Fig. 1).

IF result of RAR $\alpha$ and NLS-RAR $\alpha$ in different cell lines. $\mathrm{RAR} \alpha$ belongs to a family of nuclear receptors, and was revealed to localize to the nucleus and the cytoplasm. Although NLS-RAR $\alpha$ localized to the nucleus and cytoplasm, the cytoplasmic level was far lower compared with the nuclear levels (Fig. 2A and B). Similar results were also obtained for leukemia cell lines (Fig. 2C and D). Calculation of the nuclear fluorescence intensity revealed that the level of NLS-RAR $\alpha$ was increased compared with that of RAR $\alpha$, and the difference was statistically significant $(\mathrm{P}<0.05$; Fig. 2E and F).

Western blot analysis of RAR $\alpha$ and NLS-RAR $\alpha$. Western blot analysis confirmed the results of IF; owing to the presence of the NLS, NLS-RAR $\alpha$ localized to the nucleus. There was a significantly increased level NLS-RAR $\alpha$ present in the nucleus compared with that in the cytoplasm $(\mathrm{P}, 0.05$; Fig. 3A and B). RXR $\alpha$, like RAR $\alpha$, belongs to the nuclear receptor family, but was expressed equally in the nucleus and cytoplasm (Fig. 3C). Western blot analysis revealed that, the distribution of $\mathrm{RXR} \alpha$ was almost equal in the nucleus and cytoplasm.

Interaction between $N L S-R A R \alpha$ and $R X R \alpha$. The retinoid signal is transduced by two families of nuclear receptors, RARs and RXRs, which formed RXR/RAR heterodimers. This means that RAR $\alpha$ and $\mathrm{RXR} \alpha$ interact with each other (21). However, whether NLS-RAR $\alpha$ and RXR $\alpha$ could 
A
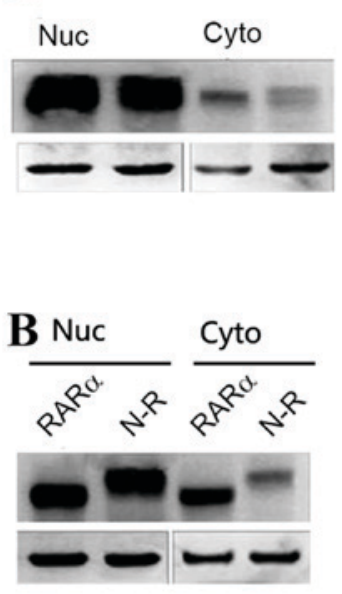

C

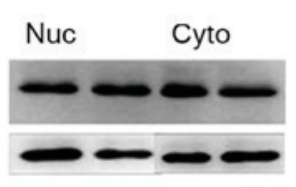

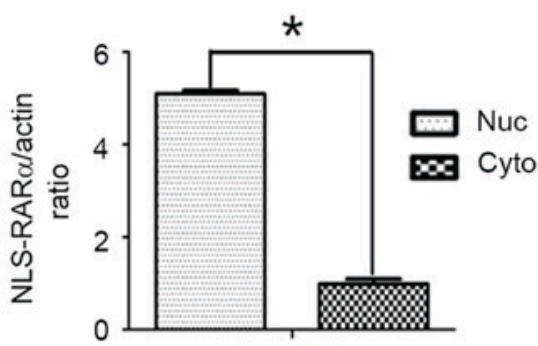

NLS-RARo
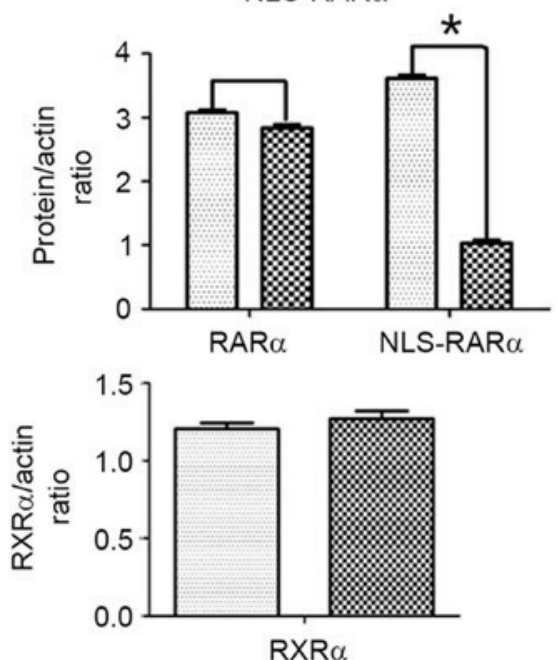

Figure 3. Expression profile of RAR $\alpha$, NLS-RAR $\alpha$ and RXR $\alpha$. (A) Western blot assay demonstrating the nuclear and cytoplasmic distribution of NLS-RAR $\alpha$ in HEK293 cells. (B and C) Western blot assay revealing the expression of (B) RAR $\alpha$ and NLS-RAR $\alpha$ (C) the distribution of RXR $\alpha$ in HEK293 cells. ${ }^{*}<0.05$. NLS-RAR $\alpha$, retinoic acid receptor- $\alpha$-nuclear localization signal fusion protein; RXR $\alpha$, retinoid X receptor- $\alpha$; N-R, NLS-RAR $\alpha$.

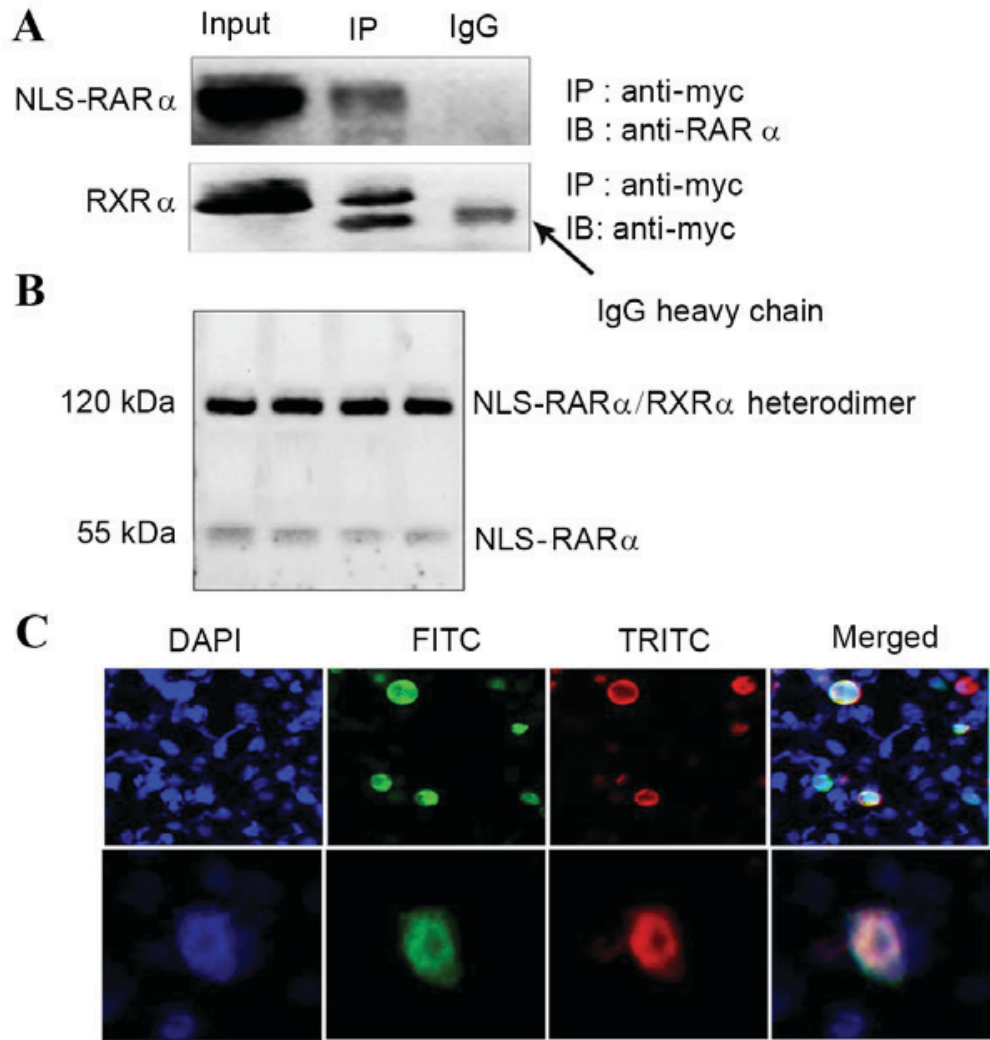

Figure 4. Interaction between NLS-RAR $\alpha$ and RXR $\alpha$. (A) Co-immunoprecipitation assay demonstrating the interaction between NLS-RAR $\alpha$ and RXR $\alpha$. (B) Native-PAGE assay demonstrating that NLS-RAR $\alpha$ and RXR $\alpha$ heterodimerize. (C) IF assay, revealing the co-localization of NLS-RAR $\alpha$ and RXR $\alpha$ (top panel magnification, x200; bottom panel magnification, x400). NLS-RAR $\alpha$, retinoic acid receptor- $\alpha$-nuclear localization signal fusion protein; RXR $\alpha$, retinoid X receptor- $\alpha$; FITC, fluorescein isothiocyanate; TRITC, tetramethylrhodamine; myc, Myc proto-oncogene protein. 
A

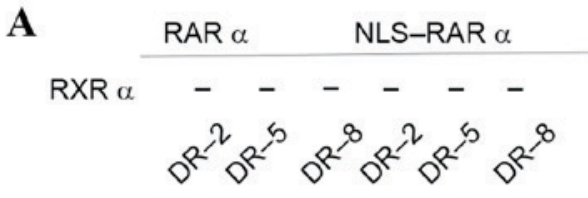

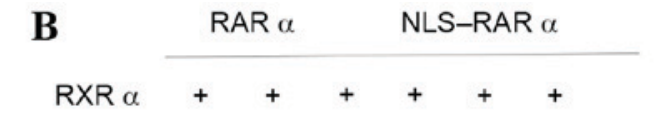
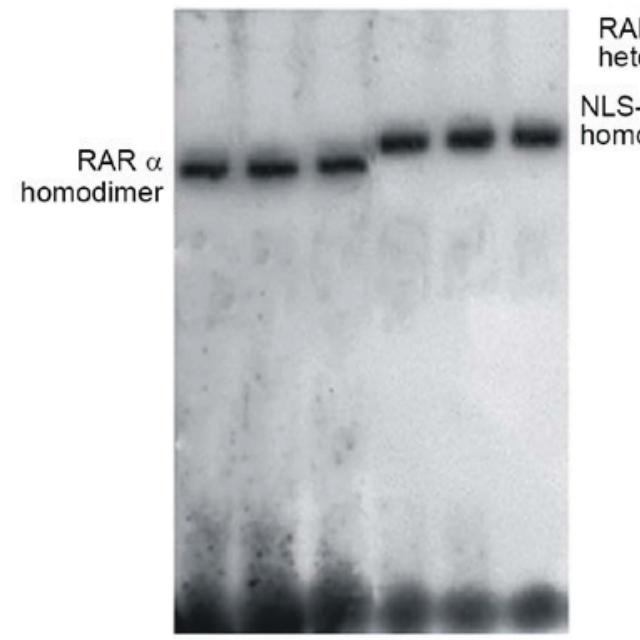

C

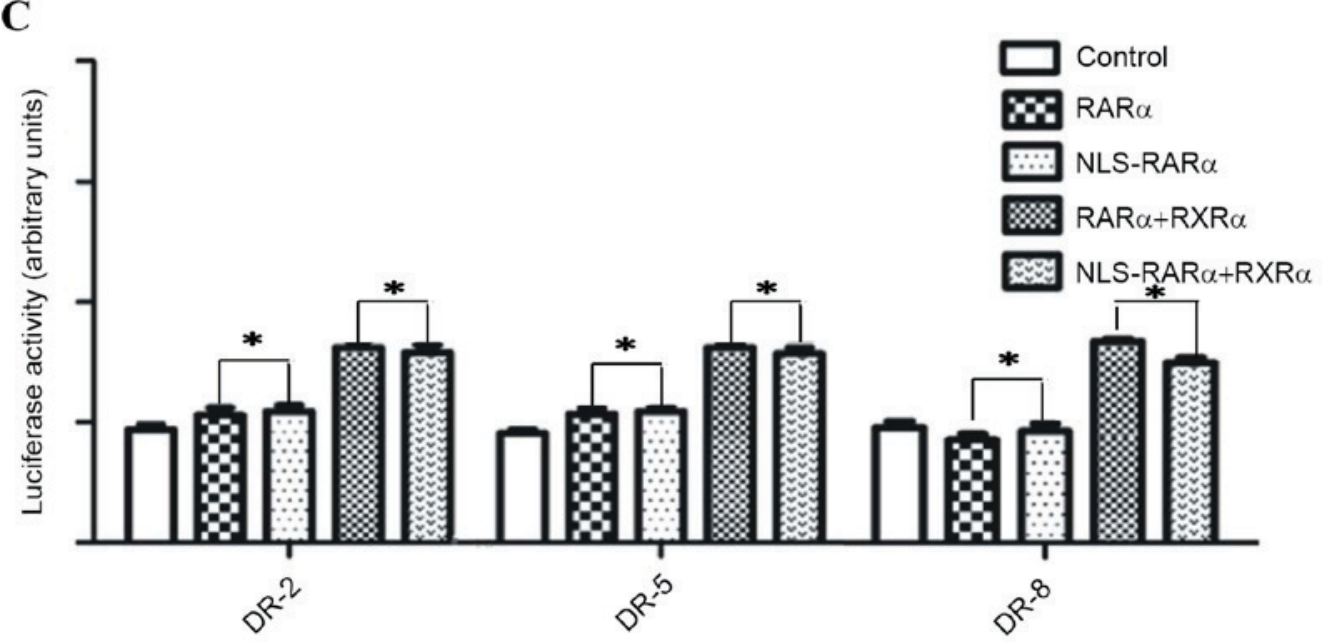

$\mathrm{N}-\mathrm{R} / \mathrm{R} \times \mathrm{R} \alpha$ heterodimer NLS-RAR $\alpha$ homodimer

Figure 5. Transcriptional activity of NLS-RAR $\alpha$. (A and B) Electrophoretic mobility shift assay demonstrating that NLS-RAR $\alpha$ bound a wider range of retinoic acid repeat elements. (C) Luciferase reporter assay demonstrating the luciferase activity resulting from NLS-RAR $\alpha$ binding to DRs and activating luciferase transcription. $\mathrm{P}<0.05$. DR, direct repeat; NLS-RAR $\alpha$, retinoic acid receptor- $\alpha$-nuclear localization signal fusion protein; RXR $\alpha$, retinoid $\mathrm{X}$ receptor- $\alpha$.

interact together was unclear. Co-imunopreciptation results revealed that NLS-RAR $\alpha$ and RXR $\alpha$ did interact (Fig. 4A). Further experiments indicated that NLS-RAR $\alpha$ and RXR $\alpha$ heterodimerized (Fig. 4B) and IF demonstrated that the two proteins co-localized (Fig. 4C).

NLS-RAR $\alpha$ may bind and regulate the activity of RAREs. Previous studies demonstrated that RAR $\alpha$ and RXR $\alpha$ could bind to specific DNA sequences or RAREs as asymmetric, oriented heterodimers in the presence of ATRA (21). Typically, RAREs are composed of two direct repeats of a core hexameric motif, PuG (G/T)TCA (20). Classical RAREs are 2, 5 and 8-bp-spaced direct repeats (referred to as DR-2, DR-5 and DR-8, respectively), and in the present study, WTRAR $\alpha$ was revealed to bind DR-2, DR-5 and DR-8 in the presence of ATRA. NLS-RAR $\alpha$ could also bind DR-2, DR-5 and DR-8 (Fig. 5A and B). The binding of NLS-RAR $\alpha$ to DR-2 and DR-5 was a little weaker than WTRAR $\alpha$, but this was not a statistically significant difference $(\mathrm{P}>0.05)$. Furthermore, results of a luciferase reporter assay revealed that NLS-RAR $\alpha$ bind the luciferase reporter plasmids and mediate their activity $(\mathrm{P}<0.05$; Fig. 5C).

\section{Discussion}

APL is characterized by the aberrant proliferation of myelocyte precursor cells, whose maturation is blocked at the promyelocyte stage of granulocytic differentiation (22). The molecular marker of APL is the $t(15 ; 17)(q 22 ; q 21)$ translocation, which yields an aberrant PML-RAR $\alpha$ fusion protein (23). In the absence of appropriate and prompt treatment, disseminated intravascular coagulation, owing to the secretion of plasminogen activators and lysosomal enzymes by leukemia cells, causes serious bleeding (24). In 1985, Huang et al (25) demonstrated that ATRA could induce complete remission, initiating a new era of APL therapy. However, a number of questions remain unanswered concerning APL. For example, the exact roles that alterations 
in RAR $\alpha$ serve in the transformation process and the associated molecular mechanisms remain unknown. In the present study, the NLS-RAR $\alpha$ fusion protein was revealed to be potentially involved in the pathogenesis of APL. NLS-RAR $\alpha$ has previously been demonstrated to promote proliferation and inhibit differentiation in the APL HL-60 cell line (26). The aim of the present study was to explain the localization of NLS-RAR $\alpha$ and assess its role as a variant transcriptional factor.

$\mathrm{RAR} \alpha$ belongs to nuclear receptor family and heterodimerizes with RXR $\alpha$ (27). The RAR $\alpha / \operatorname{RXR} \alpha$ heterodimer recognizes the RAREs DR-2 and DR-5 (25). RAREs can be identified in the promoter regions of most RA-responsive genes. In the absence of agonist, RAR $\alpha$ represses the transcription of its targets via the recruitment of several co-repressor proteins, including nuclear receptor co-repressor 2 , which maintains the chromatin in an inactive state $(13,28,29)$.

In the present study, NLS-RAR $\alpha$ was observed to localize to the nucleus to a greater degree than WTRAR $\alpha$ (Fig. 1). Changes in protein localization have been demonstrated to alter protein function, as the internal environment of the nucleus and cytoplasm are markedly different (17). The present study demonstrated the presence of an interaction between NLS-RAR $\alpha$ and RXR $\alpha$, and that NLS-RAR $\alpha$ and $\mathrm{RXR} \alpha$ could form heterodimers, which enabled them to bind RAREs. A previous study revealed that the PML-RAR $\alpha$ fusion protein could competitively bind RXR $\alpha$ in APL, forming the PML-RAR $\alpha-R X R \alpha$ oligomer, which could bind an extended repertoire of response elements (8). In the present study, the transcriptional activities of the NLS-RAR $\alpha$ variant were assessed; results from the EMSA and luciferase reporter assay indicated that the transcriptional activity of NLS-RAR $\alpha$ was the same as WTRAR $\alpha$, as NLS-RAR $\alpha$ could also bind 2-DR, 5-DR and 8-DR target probes, pointing to relaxed structural constraints for DNA binding and clarifying the function of this oncoprotein.

RAR $\alpha$ binds to several genes involved in cell cycle regulation and transformation, including tumor necrosis factor superfamily member 13 (aproliferation-inducing ligand) (30), cyclin D1 and fibroblast growth factor 18 (31). The NLS-RAR $\alpha$ fusion protein may interrupt the interaction between RAR $\alpha$ and its target proteins through its stronger binding affinity to RAREs. How NLS-RAR $\alpha$ competitively binds to RAR $\alpha$ target genes and proteins requires further study.

In conclusion, the variant protein NLS-RAR $\alpha$ promoted proliferation and inhibited differentiation in leukemia cells, and its localization was altered by the addition of NLS. As RAR $\alpha$ is a transcriptional factor, the transcriptional activities of NLS-RAR $\alpha$ were assessed and revealed to be similar to WTRAR $\alpha$. Therefore NLS-RAR $\alpha$ may serve a role in APL pathogenesis by competitively binding RAR $\alpha$-target proteins as a variant transcriptional factor; however, further research is required to identify the proteins involved. The present study illuminated the function of NLS-RAR $\alpha$ in APL, the molecular mechanism network of APL formation, and may aid with a greater understanding of APL.

\section{Acknowledgements}

The authors would like to thank Professor de The (Institut Universitaire d'Hématologie, Université Paris-Diderot, Paris,
France) for providing the luciferase report plasmid. This study was supported by grants from the National Natural Science Foundation of China (grant no. 81171658) and the Natural Science Foundation Project of Chongqing Science and Technology Commission (grant no. 2011BA5037).

\section{References}

1. de Thé H, Le Bras M and Lallemand-Breitenbach V : The cell biology of disease: Acute promyelocytic leukemia, arsenic, and PML bodies. J Cell Biol 198: 11-21, 2012

2. Zelent A, Guidez F, Melnick A, Waxman S and Licht JD: Translocations of the RARalpha gene in acute promyelocytic leukemia. Oncogene 20: 7186-7203, 2001

3. Melnick A and Licht JD: Deconstructing a disease: RARalpha, its fusion partners and their roles in the pathogenesis of acute promyelocytic leukemia. Blood 93: 3167-3215, 1999

4. Chang KS, Stass SA, Chu DT, Deaven LL, Trujillo JM and Freireich EJ: Characterization of a fusion cDNA (RARA/myl) transcribed from the $\mathrm{t}(15 ; 17)$ translocation breakpoint in acute promyelocytic leukemia. Mol Cell Biol 12: 800-810, 1992.

5. Zhou GB, Chen SJ and Chen Z: Acute promyelocytic leukemia: A model of molecular target based therapy. Hematology 10 (Suppl 1): S270-S280, 2005

6. Raelson JV, Nervi C, Rosenauer A, Benedetti L, Monczak Y, Pearson M, Pelicci PG and Miller WH Jr: The PML/RAR alpha Oncoprotein is a direct molecular target of retinoic acidin acute promyelocytic leukemia cells. Blood 88: 2826-2832, 1996

7. Zhou J, Pérès L, Honoré N, Nasr R, Zhu J and de Thé H: Dimerization-induced corepressor binding and relaxed DNA-binding specificity are critical for PML/RARA-induced immortalization. Proc Natl Acad Sci USA 103: 9238-9243, 2006.

8. Kamashev D, Vitoux D and De Thé H: PML-RARA-RXR oligomers mediate retinoid and rexinoid/cAMP cross-talk in acute promyelocytic leukemia cell differentiation. J Exp Med 199: 1163-1174, 2004

9. Zhu J, Nasr R, Pérès L, Riaucoux-Lormière F, Honoré N Berthier C, Kamashev D, Zhou J, Vitoux D, Lavau C and de The H: RXR is an essential component of the oncogenic PML/RARA complex in vivo. Cancer Cell 12: 23-35, 2007.

10. Vitaliano-Prunier A, Halftermeyer J, Ablain J, de Reynies A, Peres L, Le Bras M, Metzger D and de Thé H: Clearance of PML/RARA-bound promoters suffice to initiate APL differentiation. Blood 124: 3772-3780. 2014.

11. Ablain $\mathrm{J}$ and de The $\mathrm{H}$ : Revisiting the differentiation paradigm in acute promyelocytic leukemia. Blood 117: 5795-5802, 2011.

12. Huang Y, Qiu J, Chen G and Dong S: Coiled-coil domain of PML is essential for the aberrant dynamics of PML-RARalpha, resulting in sequestration and decreased mobility of SMRT. Biochem Biophys Res Commun 365: 258-265, 2008.

13. de Thé H and Chen Z: Acute promyelocytic leukemia: Novel insights into the mechanisms of cure. Nat Rev Cancer 10: 775-783, 2010

14. Ablain $\mathbf{J}$ and de Thé $\mathrm{H}$ : Retinoic acid signaling in cancer: The parable of acute promyelocytic leukemia. Int J Cancer 135: 2262-2272, 2014.

15. Lane AA and Ley TJ: Neutrophil elastase cleaves PML-RARalpha and is important for the development of acute promyelocytic leukemia in mice 115: 305-318, 2003.

16. Hayakawa F and Privalsky ML: Phosphorylation of PML by mitogen-activated protein kinases plays a key role in arsenic trioxide-mediated apoptosis. Cancer Cell 5: 389-401, 2004

17. Cokol M, Nair R and Rost B: Finding nuclear localization signals. EMBO Rep 1: 411-415, 2000.

18. Zhang XW, Yan XJ, Zhou ZR, Yang FF, Wu ZY, Sun HB, Liang WX, Song AX, Lallemand-Breitenbach V, Jeanne M, et al: Arsenic trioxide controls the fate of the PML-RARalpha oncoprotein by directly binding PML. Science 328: 240-243. 2010.

19. Wu TT, Chen C, Chen SM, Xu Y, Wang Y, Chen Z, Wang F, Xiao BK and Tao ZZ: Nuclear translocation of telomerase reverse transcriptase is a critical process in lymphatic metastasis of nasopharyngeal carcinoma. Oncol Lett 9: 265-269, 2015.

20. Sánchez-Quesada C, López-Biedma A and Gaforio JJ: The differential localization of a methyl group confers a different anti-breast cancer activity to two triterpenes present in olives. Food Funct 6: 249-256, 2015. 
21. Altucci L, Leibowitz MD, Ogilvie KM, de Lera AR and Gronemeyer H: RAR and RXR modulation in cancer and metabolic disease. Nat Rev Drug Discov 6: 793-810, 2007.

22. McCulloch D, Brown C and Iland H: Retinoic acid and arsenic trioxide in the treatment of acute promyelocytic leukemia: Current perspectives. Onco Targets Ther 10: 1585-1601, 2017.

23. Kakizuka A,Miller WHJr,Umesono K, Warrell RP Jr,Frankel SR, Murty VV, Dmitrovsky E and Evans RM: Chromosomal translocation $\mathrm{t}(15 ; 17)$ in human acute promyelocytic leukemia fuses RAR alpha with a novel putative transcription factor, PML. Cell 66: 663-674, 1991.

24. Choudhry A and DeLoughery TG: Bleeding and thrombosis in acute promyelocytic leukemia. Am J Hematol 87: 596-603, 2012.

25. Huang ME, Ye YC, Chen SR, Chai JR, Lu JX, Zhoa L, Gu LJ and Wang ZY: Use of all trans retinoic acid in the treatment of acute promyelocytic leukemia. Blood 72: 567-572, 1988.

26. Hu XX, Zhong L, Zhang X, Gao YM and Liu BZ: NLS-RARo promotes proliferation and inhibits differentiation in HL-60 cells. Int J Med Sci 11: 247-254, 2014.
27. de Thé H, Lavau C, Marchio A, Chomienne C, Degos L and Dejean A: The PML-RAR alpha fusion mRNA generated by the $t(15 ; 17)$ translocation in acute promyelocytic leukemia encodes a functionally altered RAR. Cell 66: 675-684, 1991.

28. Zelent A, Guidez F, Melnick A, Waxman S and Licht JD: Translocations of the RARalpha gene in acute promyelocytic leukemia. Oncogene 20: 7186-7203, 2001.

29. Bastien J and Rochette-Egly C: Nuclear retinoid receptors and the transcription of retinoid-target genes. Gene 328: 1-16, 2004.

30. Planelles L, Medema JP, Hahne M and Hardenberg G: The expanding role of APRIL in cancer and immunity. Curr Mol Med 8: 829-844, 2008.

31. Delacroix L, Moutier E, Altobelli G, Legras S, Poch O, Choukrallah MA, Bertin I, Jost B and Davidson I: Cell-specific interaction of retinoic acid receptors with target genes in mouse embryonic fibroblasts and embryonic stem cells. Mol Cell Biol 30: 231-244, 2010. 